\title{
Iatrogenic uterine perforation resulting in Richter's hernia: a rare complication of dilatation and curettage
}

\author{
Chia-Cheng Lin • Chih-Chun Lee
}

Received: 12 April 2010 / Accepted: 5 May 2010/Published online: 27 May 2010

(C) Springer-Verlag 2010

Keywords Uterine perforation · Richter's hernia . Complication

\section{Introduction}

Dilatation and curettage $(\mathrm{D} \& \mathrm{C})$ is a common diagnostic and therapeutic procedure for the gynecologic-obstetric practice. This procedure is associated with a series of complications such as bleeding, perforation, infection, and intrauterine adhesion. The overall perforation rate for first trimester abortions is around $0.8-1.3$ per 1,000 according to different authors $[1,2]$. Herein, we present a rare complication of D\&C iatrogenic uterine perforation resulting in Richter's hernia, which required segmental resection of the involved small intestine. To the best of our knowledge, we believe that this is the first case report in the literature.

\section{Case presentation}

A 32-year-old woman presented to the gynecology clinic complaining of persistent vaginal bleeding since her delivery of a 2,706-g healthy baby girl 2 weeks ago. The patient was under ergometrine for 1 week; however, her vaginal bleeding persisted. Pelvic sonogram disclosed increased endometrium

\section{C.-C. Lin · C.-C. Lee $(\square)$}

Division of General Surgery, Department of Surgery,

Taipei Medical University-Wan Fang Hospital,

No.111, Sec. 3, Xinglong Rd., Wenshan Dist.,

Taipei 11696, Taiwan (R.O.C.)

e-mail: philamo@gmail.com

C.-C. Lin

e-mail: alelin@yahoo.com thickness (about $15.3 \mathrm{~mm}$ ). Under the impression of placenta retention, the patient was admitted for D\&C with suction. The procedure was uneventful; however, approximately $2 \mathrm{~h}$ after the procedure, the patient began to feel severe abdominal pain when she was still in the recovery room. Laparoscopic exploration revealed uterine perforation with a segment of small intestine partially herniated over the perforated site (Fig. 1). General surgeon was then consulted, and the segment of small intestine was reduced from the uterine perforation hole (about $1 \times 1 \mathrm{~cm}$ in size). The uterine perforation was repaired. The involved small intestine was located at about $90 \mathrm{~cm}$ proximal to the ileocecal valve. A circular ischemic patch of small bowel on the antimesenteric border was noticed (Fig. 2). The involved small intestine was resected segmentally. The postoperative course was uneventful, and the patient was discharged under a stable condition.

\section{Discussion}

Richter's hernia is defined as "an abdominal hernia in which only part of the circumference of the bowel is entrapped in the hernial orifice" [3]. This will result in a rapid progression of the involved intestine to strangulation and perforation.

In 1606, Fabricius Hildanus described a 63-year-old women who suffered from right inguinal hernia; later, the disease was complicated by intestinal perforation and subsequent enterocutaneous fistula; fortunately, the enterocutaneous fistula closed spontaneously after 2 months, and this lady recuperated completely. This is probably the first description of Richter's hernia in the literature [3]. With the advancement of laparoscopic surgery and the use of large ports (10 $\mathrm{mm}$ or more), an increase of 
Fig. 1 The small intestine was partially herniated into the perforation hole of the uterus
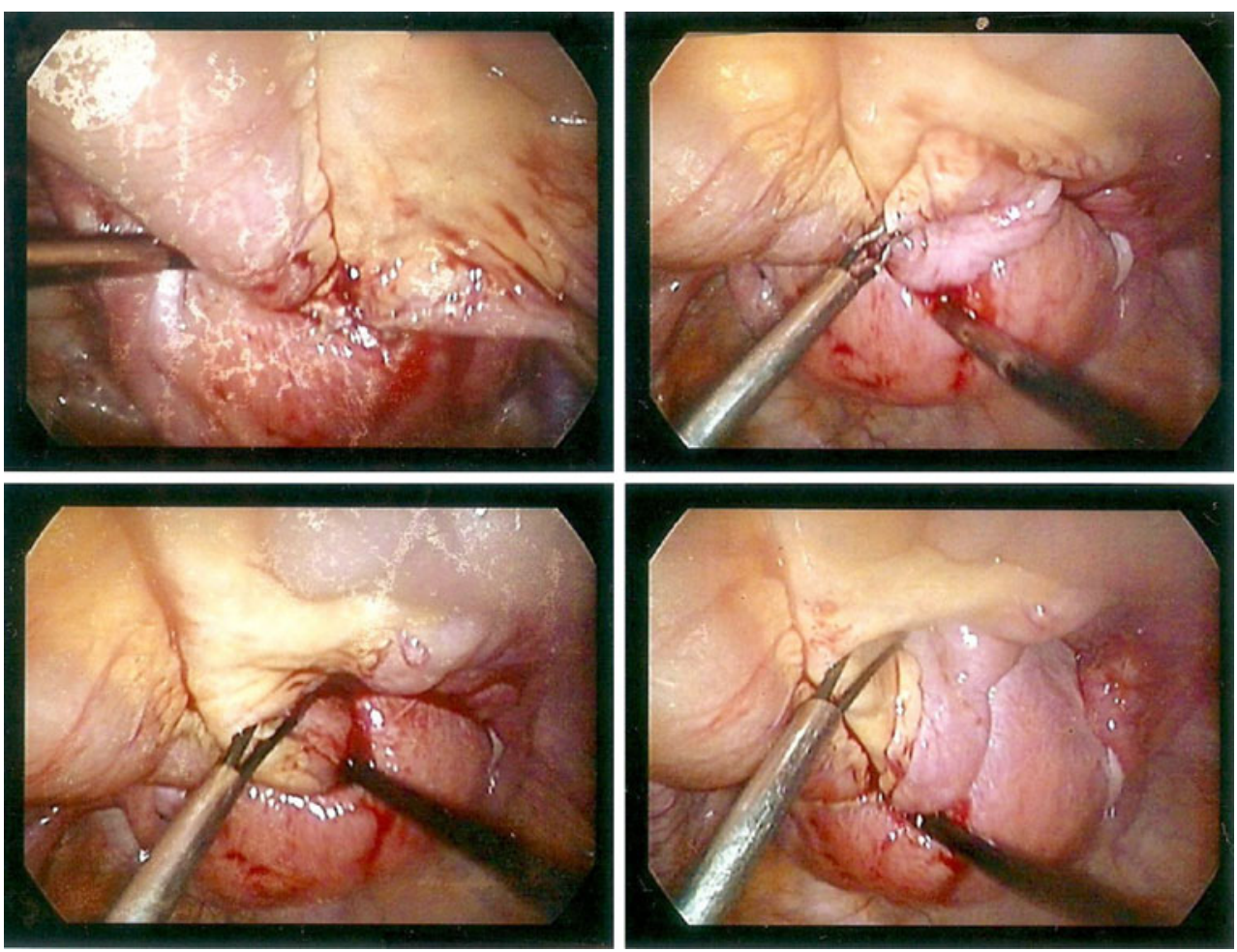

Richter's hernia at trocar sites has been reported [4, 5]; however, Richter's hernia is rarely mentioned in the literature of gynecology.

In spite of an extensive search in the medical literature, only a small number of reports about iatrogenic uterus perforation associated with internal herniation of small intestine could be found [6-9]. D\&C is a common and almost daily procedure in certain gynecologic practice. According to some authors, the inexperience of the physician is one of the risk factors of uterine perforation; unfortunately, D\&C is still performed "underground" by unqualified physicians in some countries [7]; therefore, the real complication rate of $\mathrm{D} \& \mathrm{C}$ is perhaps underestimated. When the iatrogenic uterine perforation and the herniation of small intestine occurs simultaneously, the diagnosis may be established quickly by the sonographic finding of

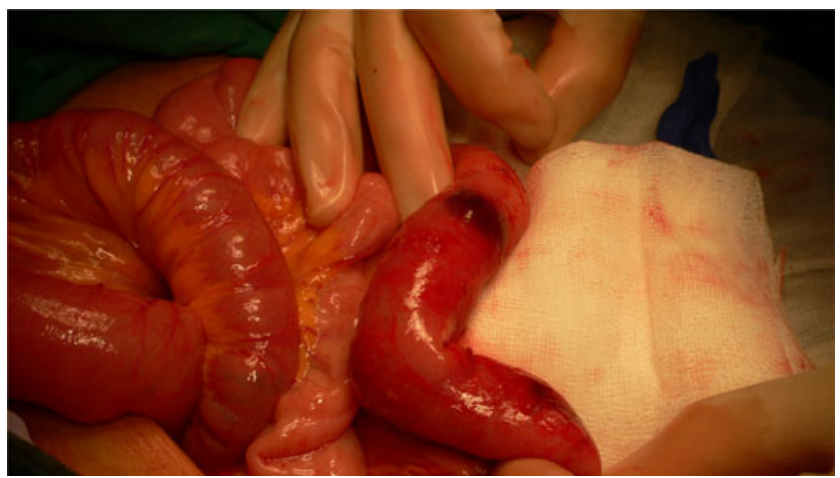

Fig. 2 After reduction, the herniated small intestine showed ischemic change intestine loop inside the uterine cavity; in more severe cases, the herniated small intestine may even be found prolapsing to the vagina or vulva. However, when the perforation hole is small, only part of the circumference of the bowel will be entrapped in the hernial orifice, making the diagnosis very difficult.

\section{Conclusion}

Physicians who practice D\&C should be aware of any unusual abdominal pain after the procedure, because early detection and management is the key to avoid disastrous outcome after iatrogenic uterine perforation.

Conflict of interest The authors report no conflicts of interest. The authors alone are responsible for the content and writing of the paper.

\section{References}

1. Chen LH, Lai SF, Lee WH, Leong NK (1995) Uterine perforation during elective first trimester abortions: a 13-year review. Singapore Med J 36(1):63-67

2. Kaali SG, Szigetvari IA, Bartfai GS (1989) The frequency and management of uterine perforations during first-trimester abortions. Am J Obstet Gynecol 161(2):406-408

3. Wolfgang Steinke, Zellweger Rene' (2000) Richter's hernia and Sir Frederick Treves: an original clinical experience, review, and historical overview. Ann Surg 232(5):710-718 
4. Boughey JC, Nottingham JM, Walls AC (2003) Richter's hernia in the laparoscopic era: four case reports and review of the literature. Surg Laparosc Endosc Percutan Tech 13(1):55-58

5. Bourdel N, Roman H, Lebouedec G, Lenglet Y, Accoceberry M, Canis M (2006) Richter's hernia occurring through a 5-mm laparoscopy sheath incision. Gynecol Surg 3(2):132-133

6. Dunner PS, Thomas MA, Ferreras M, Jerome M (1983) Intrauterine incarcerated bowel following uterine perforation during an abortion: a case report. Am J Obstet Gynecol 147 (8):969-970
7. Sherigar Jagannath Mala, Dalal Archana Darshit, Patel Jitu R (2005) Uterine perforation with subtotal small bowel prolapse - a rare complication of dilatation and curettage. OJHAS 4(1)

8. Kambiss SM, Hibbert ML, Macedonia C, Potter ME (2000) Uterine perforation resulting in bowel infarction: sharp traumatic bowel and mesenteric injury at the time of pregnancy termination. Mil Med 165 (1):81-82

9. McArdle CR, Goldberg RP, Rachlin WS (1984) Intrauterine small bowel entrapment and obstruction complicating suction abortion. Gastrointest Radiol 9(3):239-240 